$|\mathbf{C}| \mathbf{O}|\mathbf{P}| \mathbf{E} \mid$

publicationethics.org

\title{
DISCUSSION DOCUMENT: \\ PREDATORY PUBLISHING
}
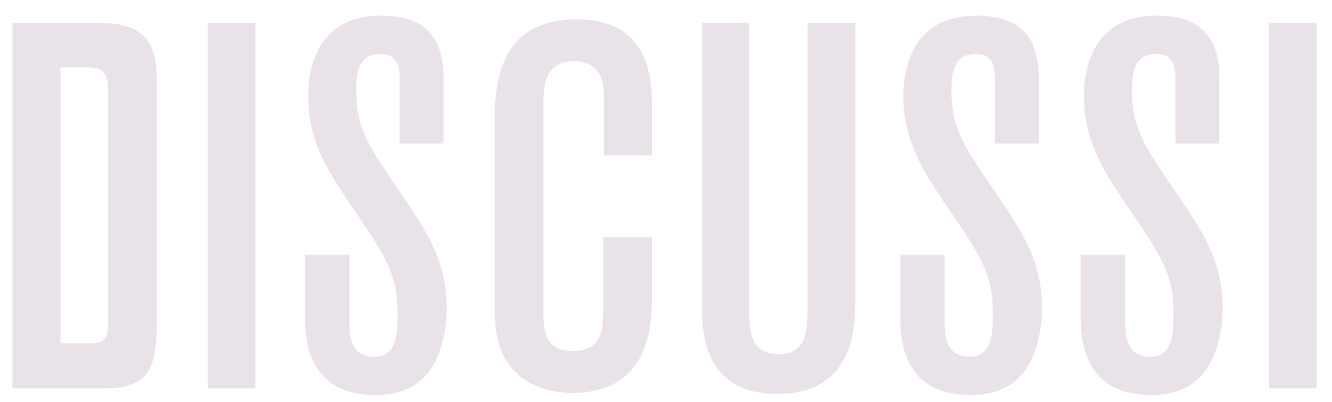


\title{
PROMOTING INTEGRITY IN RESEARGH AND ITS PUBLIGATION
}

COPE provides leadership in thinking on publication ethics and practical resources to educate and support members, and offers a professional voice in current debates.

\author{
() 2019 Committee on Publication Ethics \\ Registered charity No 1123023 \\ Registered in England and Wales, Company No 6389120 \\ Registered office: COPE, New Kings Court, Tollgate, Chandler's Ford, Eastleigh, Hampshire, SO53 3LG, United Kingdom
}

Our COPE materials are available to use under the Creative Commons Attribution-NonCommercial-NoDerivs licence https://creativecommons.org/licenses/by-nc-nd/4.0/

Attribution - You must attribute the work in the manner specified by the author or licensor (but not in any way that suggests that they endorse you or your use of the work). Non-commercial - You may not use this work for commercial purposes. No Derivative Works - You may not alter, transform, or build upon this work.

We ask that you give full accreditation to COPE with a link to our website: publicationethics.org A non-exclusive licence to reproduce this document may be applied for by writing to: cope administrator@publicationethics.org 


\section{$|\mathrm{C}| \mathbf{O}|\mathrm{P}| \mathrm{E} \mid$}

VERSION 1: November 2019

\section{$\|$}

\section{PREDATORY PUBLISHING}

\section{Introduction}

Much has been written about 'predatory publishing' over the past decade. In this discussion document, COPE will describe the basic phenomenon, identify the key issues, describe the impact on the various stakeholders involved, analyse proposed interventions and solutions, and present COPE's perspective on addressing the problem going forward. This discussion will synonymously refer to predatory publishing and predatory journals/publications as fake scholarly publishing and fake scholarly journals/publications, respectively, and will elaborate on the issues with terminology. While the focus of this discussion paper is primarily journals, there are also predatory conferences and predatory proceedings of those conferences. COPE welcomes feedback and comments from publishers, journal editors, reviewers, researchers, institutions, librarians, funders, and other stakeholders on this subject.

Please send your feedback to: Natalie Ridgeway, Executive Officer at: cope execofficer@publicationethics.org

\section{Definition of Predatory Publishing}

Predatory publishing generally refers to the systematic for-profit publication of purportedly scholarly content (in journals and articles, monographs, books, or conference proceedings) in a deceptive or fraudulent way and without any regard for quality assurance. Here, 'for-profit' refers to profit generation per se. Whereas predatory publishers are profit-generating businesses, some may conceivably pose as non-profit entities such as academic societies or research institutions. This is not to suggest that 'for profit' is, in itself, problematic but that these journals exist solely for profit without any commitment to publication ethics or integrity of any kind.

Predatory publishers may cheat authors (and their funders and institutions) through charging publishing-related fees without providing the expected or industry standard services. Predatory publishers may also deceive academics into serving as editorial board members or peer reviewers. In short, fake scholarly publications lack the usual features of editorial oversight and transparent policies and operating procedures that are expected from legitimate peer-reviewed publications.

It is widely recognised that the phenomenon of predatory publishing grew with the emergence of online publishing, coupled with a widespread academic climate of research evaluation linked to journal title prestige and journal-level metrics. Although there is currently no single agreed-upon definition of predatory publishing, ${ }^{1}$ Jeffrey Beall, an American academic university librarian, first used the term 'predatory' in the context of publishers and journals exploiting the author-pays business model of online 'gold' open-access publishing. ${ }^{2}$ Consequently, predatory publishing is sometimes confused with non-predatory open-access publishing. 


\section{$|\mathrm{C}| \mathbf{O}|\mathbf{P}| \mathbf{E} \mid$}

The profitability of predatory publications primarily comes from a publishing fee (eg, supposedly as an article processing charge or APC, also called an article publishing charge, article publication charge, or author publication charge) that is mandatory and made a condition for publication but without the accompanying standard academic publishing services that are part of the normal vetting and production processes of scholarly publications. Publishing fees of predatory publications are assumed to be high, ${ }^{3}$ but are often only about US $\$ 100.4$ Publishing fees are typically not mentioned on a predatory publication's website. Sometimes, instead of being payable after manuscript acceptance, publishing fees are charged by a predatory publisher at the time of manuscript submission and then banked without the delivery of any promised or standard services. Predatory publishers may even publish manuscripts without waiting for APC payments so as to build their article archive.

In some cases, there may be a misleading statement such as "no submission fee". Then, compulsory fees are announced to authors for the first time in their acceptance letter as a condition of manuscript acceptance. These owed fees supposedly pay for publishing and/or peer review administration, a mandatory set number of hardcopy reprints, or mandatory aspects of production such as copy editing. The latter may be non-existent or performed in a substandard way by the journal/publisher or by a nominated company that may have an undisclosed financial relationship with or may be owned by the journal/publisher. Some predatory publishers also organise fake conferences and publish associated conference proceedings. As with predatory publishing generally, these fake conferences violate all of the norms of scholarly vetting and often identify legitimate scholars as academic advisors to the conference, when in fact these individuals have no involvement or even knowledge that their names are associated with the organisation of the bogus conference.

\section{CHARACTERISTICS OF PREDATORY PUBLICATIONS}

Attempts at definitive descriptions of predatory publishers have frequently been criticised as either being incomplete or capturing features that may legitimately exist within the complex range and diversity of scholarly publications. Some definitions of predatory publishing say that authors are charged a submission and/or publishing fee, which some legitimate publishers also charge, but the predatory publishers misrepresent the expected level of services, such as peer review and copy editing, that are provided by legitimate publishers. ${ }^{6 *}$

Commonly co-occurring features that may sufficiently characterise predatory publications are:

- Hidden or unclear author fees,

- The lack of quality peer review of articles by experts in the field, and

- The guarantee of acceptance and/or the promise of very fast publication times (eg, within one week or 48 hours).

* It should be noted that not all legitimate author-pays open-access journals include copy-editing service costs in their author fee or provide copy-editing services. Furthermore, not all legitimate journals are indexed in respected indexes that many treat as whitelists/safelists. There is a range of quality in academic journals and it should be noted that some non-predatory journals may not be good examples of best-practice journals. 
Thus, it could be argued that the main hallmark of predatory publishing is simply that there is no or minimal quality control over the scholarly material in the publications (akin to practices of 'vanity presses'). Predatory publications are either silent about peer review or make false claims that the journal is peer reviewed. Another feature which is commonly noted is aggressive emailed solicitation for papers that are frequently outside of the scope of expertise of those receiving the solicitation.

Predatory publishers may also be unethical in other ways, such as plagiarising content in order to appear as having archived articles/issues, selling authorship, allowing authors to publish plagiarised or questionable content, and infringing or allowing authors to infringe copyright and trademarks. Requests by authors to withdraw their articles or chapters are generally either ignored or not acted upon (eg, COPE Forum case 16-22). ${ }^{7}$ Predatory publishers are also known to charge a high fee for the withdrawal of a manuscript, if they withdraw the manuscript at all.

Other possible indicators of predatory publishing may include:

- Incomplete or misleading reporting of policies (including copyright and user licenses), processes, personnel, performance, and affiliations in the journal's website or correspondence,

- Poor language usage (including poor grammar) and low production quality, both in the presentation of the journal's description and guidelines, and in some of the articles that are published,

- The lack of ethics policies and need for ethics declarations, particularly related to animal and human studies, conflicts of interest, and study funding,

- The lack of any corrections/retractions of articles, and

- The lack of ability for articles to be retrieved on an electronic search platform in perpetuity, or for articles to be retrieved at all despite being listed in a table of contents.

Predatory publishers commonly advertise false or misleading information and claim copyright of the articles but only erratically publish accepted content, if at all. Other fraudulent information may include a fictitious rejection rate, a falsely created impact factor, false claims of indexing in real indexes or true claims of being indexed in bogus indexes, or the adoption of the imprimatur logo of a membership organisation with a false claim of being a member in good standing. While organisations such as COPE work vigilantly to ensure that their logos are not replicated falsely, violations do occur.

For those assessing whether a journal is legitimate or fake, initial checks should include the assessment of the scholarly status of the editor-in-chief, who may be non-existent, non-identifiable or lacking in appropriate academic credentials, relevant employment, and/or relevant experience. A further possible sign of a predatory publisher is if the owner or publisher is also the editor-in-chief. ${ }^{4}$ Some journals have non-professional email addresses such as gmail.com and odd organisational mailing addresses such as PO Boxes. Furthermore, false claims are frequently made about the legitimacy of editorial boards. Problems with predatory publications range from non-existent editorial boards to fraudulent claims that some legitimate scholars sit on a board, when in fact they may have never given their permission or actually been invited as editorial board members. Requests by scholars to withdraw their names from editorial board lists are generally either ignored or not acted upon. 


\section{$|\mathrm{C}| \mathbf{O}|\mathrm{P}| \mathrm{E} \mid$}

Some organisations and researchers have published lists of key warning signs of predatory journals. ${ }^{1,4,6,8}$ Many warning signs represent the opposite of the Principles of transparency and best practice in scholarly publishing of COPE, the Directory of Open Access Journals (DOAJ), the Open Access Scholarly Publishers Association (OASPA), and the World Association of Medical Editors (WAME). ${ }^{9}$

It may be useful to adapt the $\mathbf{1 6}$ Principles of transparency as a framework of warning signs that may indicate the presence of a fake journal, especially if multiple signs occur together.

\section{Warning signs of fake journals, based on the 16 Principles of transparency:}

1. Website: The journal's website contains misleading or false information (eg, indexing, metrics, membership of scholarly publishing organisations), lacks an ISSN or uses one that has already been assigned to another publication, mimics another journal/publisher's site, or has no past or recent journal content.

2. Name of journal: The journal name is the same as or easily confused with that of another; scope, or association.

3. Peer review process: Peer review and peer review process and model are not mentioned, or manuscript acceptance or a very short peer review time is guaranteed. Submitted manuscripts receive inadequate or no peer review.

4. Ownership and management: Information about the ownership and/or management is missing, unclear, misleading, or false.

5. Governing body: Information on the editorial board is missing, misleading, false, or inappropriate for the journal; full names and affiliations of editorial board members are missing.

6. Editorial team/contact information: Full names and affiliations of the journal's editor/s and full contact information for the editorial office are missing, the editor-in-chief is also the owner/publisher, or the editor-in-chief is also the editor of many other journals, especially in unrelated fields.

7. Copyright and licensing: Policies and notices of copyright (and publishing licence and user licence) are missing or unclear.

8. Author fees: Mandatory fees for publication are not stated or not explained clearly on the journal website, submission system, or the letter of acknowledgement and/or are revealed only in the acceptance letter, as a condition of acceptance.

9. Process for identification of and dealing with allegations of research misconduct: There is no description on how cases of alleged misconduct are handled.

10. Publication ethics: There are no policies on publishing ethics (eg, authorship/contributorship, data sharing and reproducibility, intellectual property, ethical oversight, conflicts of interest, corrections/retractions). 
11. Publishing schedule: The periodicity of publication is not indicated and/or the publishing schedule appears erratic from the available journal content.

12. Access: The way(s) in which content is available to readers, and any associated costs, is not stated, and in some cases listed articles are not available at all.

13. Archiving: There is no electronic backup and preservation of access to journal content (despite such claims).

14. Revenue sources: Business models, business partnerships/agreements, or revenue sources are not stated; publishing fees or waiver status are linked to editorial decision making.

15. Advertising: Advertising policy is not given, or advertisements are linked to editorial decision making or are integrated with published content.

16. Direct marketing: Direct marketing is obtrusive and gives misleading or false information.

\section{DECEPTION BY FALSE FAMILY RESEMBLANCE}

One common characteristic of a predatory or fake scholarly journal is a fraudulently 'stolen' title or one used without permission. The counterfeit journal thus adopts a credible and recognisable title of an existing journal. By doing this, predatory publishers fraudulently aspire to fool potential authors into believing that they are sending their manuscript to the real, credible journal. An online fake journal may even steal the name of a print-only journal, ${ }^{10}$ or copy the name and also website and fee structure of a journal but have a slightly different URL (known as journal hijacking) by which to bypass author fees to a different bank account. A predatory publisher may create a website posing as a submission platform for multiple hijacked journal titles.

Alternatively, these journals create titles that are confusingly very similar to well-known and established journals. For example, a hypothetical, well-established journal such as the Journal of epistemological existentialism (non-existent as far as we know) will be changed to a fake journal called the Epistemological existentialism journal, in the hope that prospective authors will confuse the two. A fake journal could also pose as a related version of a real journal that does not have another edition (eg, International journal of epistemological existentialism or Journal of epistemological existentialism A).

Thus, the focus of predatory or fake scholarly journals is to mirror real journals sufficiently so as to confuse and attract naive or uninformed academics to submit their manuscripts to these journals. The purpose here is to resemble (ie, create a 'family resemblance' to), as much as possible, legitimate journals. Recent research has illustrated, however, that such attempts are façades that do not fool everyone and some authors knowingly submit their manuscripts to journals which they recognise as predatory. Who publishes in predatory journals and what are the motives for doing so will be discussed later in this document. It should be further noted that these strategies are similar to those used in some invitations to serve on editorial boards. 


\section{$|\mathrm{C}| \mathrm{O}|\mathrm{P}| \mathrm{E} \mid$}

\section{RECRUITMENT STRATEGIES OF PREDATORY JOURNALS}

As Carroll (2016), ${ }^{11}$ and other authors note, one hallmark of predatory publishers is massive 'cold calling' invitation campaigns to publish in their journal. There are a number of tips to recognising these invitations as perpetrated by predatory or fake scholarly journals. As Eriksson and Helgesson (2017) note with respect to what they term "rogue publishers" and "false academy", there is now a "familiar piracy practice of spamming researchers' email boxes with offers to submit papers in areas they know little or nothing about...".12 Other experiences include generic invitations with grammatical errors and false or misleading information that are frequently sent by editorial offices rather than by a recognisable editor-in-chief with a legitimate institutional affiliation. More sophisticated invitations may contain a personal salutation and reference to a named, legitimate publication that the author has published. These latter types of invitations are often filled with flowery praise of the importance of the author and the mentioned publication.

\section{WHAT'S IN A NAME?}

As noted at the start of this discussion paper, publishers who falsely present journals, proceedings, and monographs as the products of rigorous peer review and oversight by appropriately credentialed and experienced editors-in-chief and editorial boards are frequently referred to as predatory publishers. The debate about this identifier has included a discussion about the nature of identifying fake journals as predatory.

For those unhappy with the label, it can be noted that the term 'predatory' (or similar names such as parasitic, scam, fraudulent, and deceptive) suggests victim authors and predation against these authors by these types of publishers. The most obvious meaning of victim in this context has been those who innocently fall prey to submitting their manuscripts to these journals. For the innocent, the harm can be great. The authors pay for but receive no service at all in improving their research and, further, may find their reputations impugned when it is discovered that the journal in which their article appears is a fake journal. They are lied to and come to realise the magnitude of the lies if they unfortunately accepted at face value the false statements about the status of the journal, including fake reviewing, fake impact factors, and other false statements about the legitimacy and reputation of the journal. This harm generally cannot be mitigated by withdrawal or retraction of the article, as predatory journals are known for their refusal to withdraw or retract anything that is published under their name. To add insult to injury, an article appearing in a fake journal cannot be submitted for publication in a legitimate journal, as that counts as attempted redundant/duplicate publication.

The main reason that critics of the 'predatory' terminology have objected at least partially is because, according to a number of studies, some authors knowingly submit articles for publication in fake scholarly journals. Critics believe that it is important to acknowledge culpability on the part of authors who knowingly publish in such journals, ${ }^{13}$ and believe, consequently, that the term 'predatory' is a misdescription.

By extension, individuals whose names are included in editorial boards and reviewer panels of fake journals without their knowledge or permission are victim to a form of identity theft and also guilt by association. However, some individuals may agree or request to be listed in such editorial boards in an attempt to augment their resumes. 


\section{OTHER STAKEHOLDERS}

Having acknowledged the main problem with the term 'predatory publishing', it is important to note that there are other stakeholders in academic publishing who may be harmed by fake scholarly publications. If a stakeholder perspective is adopted, the question arises of who else might be a victim of predatory publishers. One fairly obvious set of candidates is the legitimate open-access journals that operate with standard best practices as outlined by COPE and other industry organisations. Meeting the criteria for membership in COPE or the Open Access Scholarly Publishers Association (OASPA) or the listing of a journal in the Directory of Open Access Journals (DOAJ) serve to distinguish legitimate scholarly open-access journals from fake or predatory open-access journals. In addition, whereas legitimate openaccess journals often do utilise a fee structure as a mechanism to cover the costs of review, administration, oversight, and production (which may or may not include copy editing), some journals do not charge any fee (so-called platinum or diamond open-access journals). Still, bogus players in the field of scholarly publishing may create confusion that is harmful to the overall reputation of legitimate open-access journals.

Publication in a fake journal usually precludes re-publication in a legitimate journal and thus wastes resources and research funding. Occasionally, upon author explanation an editor will consider an article previously accepted by a fake journal. Generally, however, this is not the case. Thus, if the research is legitimate and meritorious, the knowledge is not disseminated or cited through the normal knowledge-sharing mechanisms. Conversely, fake or unethical research that does get published in fake journals may pollute the archive and possibly affects later research and meta-analyses. Research that has not been properly peer reviewed but published in a fake journal may harm society if translated into practice or policy. Pharmaceutical companies have been reported to publish clinical research in predatory journals. ${ }^{14}$

Furthermore, when there is public exposure of predatory journal scandals, research and its funding sources may be harmed in other ways. The public may interpret these scandals as evidence that government funding of research should not be supported in the future, for violations of research and publication integrity may occur. This judgement may also extend to questioning the legitimacy of funding public universities. In these cases, the existence of these journals may, in fact, cause harm that has a negative impact on knowledge creation and dissemination more broadly.

Finally, human participants in biomedical and some social science research accept some risk to themselves to further knowledge. When the research findings end up with a predatory publisher, the good will of participants and the knowledge that comes from their participation comes to naught.

Noting the issue of more general potential harm to other stakeholders does not imply that the term 'predatory' should be endorsed. While there is no general consensus on the terminology, descriptions are important and should meaningfully describe what is being defined. The umbrella term 'bad faith' has been suggested, ${ }^{15}$ but seems opaque as a definitional term. Meanwhile, the term 'questionable journals"16 may be too vague and include low-quality or young but legitimate journals. While pointing out the challenges with terminology, COPE is consequently neutral about imposing terminology on this complex phenomenon. 


\section{$|\mathrm{C}| \mathrm{O}|\mathrm{P}| \mathrm{E} \mid$}

\section{WHICH SCHOLARS PUBLISH IN THESE JOURNALS AND WHY?}

While there is no consensus of opinion as to which scholars publish in these journals and why, some research has been done which suggests that the largest number of such authors are geographically from countries in Asia and Africa. ${ }^{5}$

Further, it has been argued that the pressure to publish in academia fosters motivation to access the fast cycle of fake or predatory publishers. Curry and Lillis (2018) have argued that the dominance of the English language as the language of scholarly research and citation discriminates against those for whom English is a second language..$^{17}$ This may further entice some scholars to submit to fake journals. Other studies (eg, Frandsen, 2019'16) suggest that some scholars may just be naive or innocent.

Other research has confirmed that academics from North America and Europe also publish in fake or predatory journals. Recently, Offord (2018) reported on an in-depth journalistic inquiry which confirmed that at least 5000 German academics knowingly published articles in such journals. ${ }^{18}$

\section{JUST ANOTHER CASE OF BUSINESS ETHICS GONE WRONG: MORAL AND LEGAL RESPONSES}

There are two main approaches to addressing the problem of fake or predatory publishers. One is to examine, expose, analyse, and educate through scholarly research on the topic; raise wider awareness through journalistic articles on the players and scope of the problem; and provide guides and other forms of education to prospective authors. The other approach is to criminalise the behaviour and utilise the court system in an attempt to penalise the owners and producers and exert the force of the law in terms of heavy fines. Both of these approaches are complementary and often characteristic to similar approaches to other violations of business ethics.

Ultimately, whatever the motivation may be for authors, the existence of these journals is bad.

The journals violate legal norms and moral norms. They are parasitic on scholarly publications and require direct action. As noted above, some services believe caveat emptor is the best approach and provide check lists and identifying characteristics to warn and educate the innocent. Some believe lists of good publishers and fake publishers should be publicly accessible. Some groups (eg, Cabells) provide such lists but they are sometimes paywall protected and expensive.

A recent example of the criminalisation approach was a legal complaint made to the court in the United States in 2016. In this example, the US Federal Trade Commission won a court case against the OMICS Group Inc. and their companies in 2019, citing that they made deceptive marketing claims about their journals and conferences and hid publication fees. The court imposed a fine of approximately US $\$ 50.1$ million on OMICS. ${ }^{19}$ 


\section{GENERAL ADVICE AND APPROACH GOING FORWARD}

As a member organisation with the mandate to provide education and expertise on matters related to excellence in publication ethics, COPE provides this discussion document as an educational service. Below are some suggested actions for selected stakeholders to take so as to tackle, avoid, and raise awareness of the problem of predatory journals.

\section{AUTHORS, PROFESSIONAL SOCIETIES, AND INSTITUTIONS:}

a) Educate researchers, supervisors, librarians, and administrators in publishing literacy and about fake journals (see the list of warning signs above based on the 16 Principles of transparency).

b) Identify trustworthy journals through the 'Think.Check.Submit.' campaign. (https://thinkchecksubmit.org/)

c) Create and continually update community and discipline-specific journal whitelists/safelists using clear criteria, similar to the 'Directory of nursing journals' jointly maintained by Nurse author \& editor and the International academy of nursing editors. (https://nursingeditors.com/journals-directory/)

d) Verify spam invitations, made by email, text message, or telephone call, to submit manuscripts (eg, research papers or invited reviews) or attend conferences. Consider using the DNS Checker to check the Internet Protocol of suspected spam. (https://dnschecker.org/ip-blacklist-checker.php)

e) Check journal names, ISSN codes, and URLs are real ones; verify any claimed metrics, indexed status, and organisational membership. Check that researcher profiles on institutional websites or Linkedln mention claimed editorship of journals.

f) Read a sample of archived articles from potential target journals to check quality. Avoid citing predatory journal articles and beware when performing systematic and meta-analyses.

g) Beware of paying author fees, especially those that are suddenly demanded as a condition of acceptance, without checking what they are for, and assigning copyright to a predatory journal. Demand manuscript withdrawal if payment has not yet been made and/or copyright has not yet been assigned as a condition of acceptance (see COPE Case number 16-22. Withdrawal of accepted manuscript from predatory journal.) (https://bit.ly/2LaYOY4) 


\section{$|\mathrm{C}| \mathbf{O}|\mathrm{P}| \mathrm{E} \mid$}

\section{GENERAL ADVICE AND APPROACH GOING FORWARD (CONT.):}

\section{FUNDERS AND INSTITUTIONS:}

a) Discourage publication in predatory journals and discourage citation of articles in predatory journals.

b) Exercise caution in the use of journal metrics during research assessments and staff appraisals.

Consider using peer review, as well as the following guidelines and recommendations:

i) San Francisco declaration on research assessment (DORA). (https://sfdora.org/)

ii) Leiden manifesto for research metrics. (https://www.leidenmanifesto.org/)

iii) The metric tide. (https://responsiblemetrics.org/the-metric-tide/)

iv) The Hong Kong principles for assessing researchers: Fostering research integrity. (https://osf.io/m9abx/)

\section{JOURNALS AND PUBLISHERS:}

a) Check that your journals adhere to the COPE/DOAJ/OASPA/WAME Principles of transparency and best practice in scholarly publishing (https://bit.ly/2IZNPYU) and COPE's Core practices. (https://bit.ly/2m2kFrN)

b) Trademark journals if possible. Periodically perform online searches of your journal and articles to check if they are being misappropriated. Consider legal action and issue cease and desist letters in cases of trademark or copyright breech.

c) Consider making use of publicly visible platforms for open review or publishing 'open reports' (peer review reports with or without reviewers' names) for transparency.

d) Write editorials to promote the 'Think.Check.Submit.' campaign and inform readers/indexes if you identify predatory versions of your journal/s.

e) Discourage citation of articles published in fake journals.

\section{REVIEWERS AND EDITORS:}

a) Periodically perform online searches of yourself to check if you appear on any journal or conference editorial boards without your knowledge or permission. Demand removal of your name if necessary.

b) Verify spam invitations, made by email, text message, or telephone call, to join reviewer panels or editorial boards. Consider using the DNS Checker to check the Internet Protocol of suspected spam. (https://dnschecker.org/ip-blacklist-checker.php).

c) Check journal names, ISSN codes, and URLs are real ones; verify any claimed metrics, indexed status, and organisational membership.

d) Discourage citation of articles published in fake journals. 


\section{SOME RESOURCES FOR GUIDANCE}

1. Principles of transparency and best practice in scholarly publishing.

Committee on Publication Ethics, Directory of Open Access Journals, Open Access Scholarly

Publishers Association, World Association of Medical Editors. (https://bit.Iy/2/zGpLo)

2. "Fake", "predatory", and "pseudo" journals: Charlatans threatening trust in science.

International Committee of Medical Journal Editors. (https://bit.ly/2kg08j3)

3. Laine C, Winker MA. Identifying predatory or pseudo-journals.

World Association of Medical Editors. (https://bit.ly/2jWvTOp)

4. Predatory or deceptive publishers - Recommendations for caution.

Council of Science Editors. (https://bit.ly/2/Sd2UQ)

5. AMWA-EMWA-ISMPP Joint position statement on predatory publishing.

American Medical Writers Association, European Medical Writers Association, International Society for Medical Publication Professionals.

(https://www.tandfonline.com/doi/full/10.1080/03007995.2019.1646535)

6. Predatory publishing. COPE Forum discussion summary.

5 November 2018. (https://bit.ly/2kzZDRh)

7. Think.Check.Submit. An online guide to help researchers identify trusted journals for their research. (https://thinkchecksubmit.org/)

8. Think.Check.Attend. An online guide to help researchers judge the legitimacy and academic credentials of conferences. (https://thinkcheckattend.org/)

In this discussion document, COPE is seeking to play a part in what is a live and ongoing debate within the scholarly publishing community, by providing an overview of the issue, along with some recommendations and resources. COPE welcomes feedback and comments from publishers, journal editors, reviewers, researchers, institutions, librarians, funders, and other stakeholders on this subject.

Please send your feedback to: Natalie Ridgeway, Executive Officer at: cope execofficer@publicationethics.org 


\section{$|\mathrm{C}| \mathrm{O}|\mathrm{P}| \mathrm{E} \mid$}

\section{REFERENCES}

1. Cobey KD, Lalu MM, Skidmore B, Ahmadzai N, Grudniewicz A, Moher D. What is a predatory journal? A scoping review [version 2; peer review: 3 approved]. F1000Research 2018;7:1001. doi:10.12688/f1000research.15256.2

2. Beall J. Predatory publishers are corrupting open access. Nature 2012;489:179. doi:10.1038/489179a

3. Clark J, Smith R. Firm action needed on predatory journals. BMJ 2015;350:h210. doi:10.1136/bmj.h210

4. Shamseer L, Moher D, Maduekwe O, et al. Potential predatory and legitimate biomedical journals: Can you tell the difference? A cross-sectional comparison. BMC Medicine 2017;15:28. doi:10.1186/s12916-017-0785-9

5. Shen C, Björk B-C. 'Predatory' open access: A longitudinal study of article volumes and market characteristics. BMC Medicine 2015;13:230. doi:10.1186/s12916-015-0469-2

6. Predatory or deceptive publishers - Recommendations for Caution. Council of Science Editors (CSE). CSE site. Visited 12 September 2019: https://bit.ly/2/Sd2UQ

7. Withdrawal of accepted manuscript from predatory journal. COPE Case number 16-22. COPE site.

Visited 12 September 2019: https://bit.ly/2LaYOY4

8. Laine C, Winker MA. Identifying predatory or pseudo-journals. World Association of Medical Editors site. 18 February 2017. Visited 12 September 2019: https://bit.ly/2jWvTOp

9. Principles of transparency and best practice in scholarly publishing. Committee on Publication Ethics, Directory of Open Access Journals, Open Access Scholarly Publishers Association, World Association of Medical Editors.

Version 3, 2018. COPE site. Visited 12 September 2019: https://bit.ly/2/zGpLo

10. Butler D. Sham journals scam authors.

Nature 2013;495:421-422. doi:10.1038/495421a

\section{AUTHOR CONTRIBUTIONS}

\section{Conceptualisation:}

Originally conceptualised by Deborah Poff.

We describe contributions to this project as follows:

Version 1:

Writing - Original draft

preparation: Deborah Poff
Writing - review and editing: Deborah Poff, Trevor Lane, and Matt Hodgkinson
11. Carroll CW. Spotting the wolf in sheep's clothing:

Predatory open access publications.

J Grad Med Educ 2016;8:662-664. https://bit.ly/2mf3KCw

12. Eriksson S, Helgesson G. The false academy: Predatory publishing in science and bioethics. Med Health Care Philos 2017;20:163-170. https://bit.ly/2mbE8GC

13. Crotty D. Predatory publishing as a rational response to poorly governed academic incentives. The Scholarly Kitchen 28 February 2017. https://bit.ly/2/wM19/

14. Deprez EE, Chen C. Medical journals have a fake news problem. Bloomberg Businessweek 29 August 2017. https://bloom.bg/2mfvS8K

15. Anderson R. Should we retire the term "Predatory publishing"? The Scholarly Kitchen 11 May 2015. https://bit.ly/2zrONCe

16. Frandsen TF. Why do researchers decide to publish in questionable journals? A review of the literature. Learned Publishing 2019;32:57-62.

https://doi.org/10.1002/leap.1214

17. Curry MJ, Lillis T. The dangers of english as lingua franca of journals. Inside Higher Ed 13 March 2018. https://bit.ly/2kC2GZf

18. Offord C. German scientists frequently publish in predatory journals. The Scientist 19 July 2018. https://bit.ly/2kOu3iv

19. Court rules in FTC's favor against predatory academic publisher OMICS Group; Imposes \$50.1 million judgment against defendants that made false claims and hid publishing fees. US Federal Trade Commission (FTC). FTC site. 3 April 2019. Visited 12 September 2019: https://bit.ly/2IRcM8G

\section{ACKNOWLEDGEMENTS}

Howard Browman, Mirjam Curno, Nancy Chesheir, Timothy Devinney, Chris Graf, Tara Hoke, Rachel Safer and Michael Wise reviewed and provided suggestions for revisions to the document. 
Our COPE materials are available to use under the Creative Commons Attribution-NonCommercial-NoDerivs licence https://creativecommons.org/licenses/by-nc-nd/4.0/

Attribution - You must attribute the work in the manner specified by the author or licensor (but not in any way that suggests that they endorse you or your use of the work). Non-commercial - You may not use this work for commercial purposes.

No Derivative Works - You may not alter, transform, or build upon this work.

We ask that you give full accreditation to COPE with a link to our website: publicationethics.org

A non-exclusive licence to reproduce this document may be applied for by writing to: cope administrator@publicationethics.org 


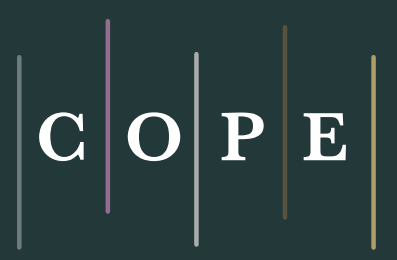

\section{publicationethics.org}

f facebook.com/publicationethics

$\vartheta$ @COPE in Linkedln

Registered charity No 1123023

Registered in England and Wales, Company No 6389120 Registered office: COPE, New Kings Court, Tollgate, Chandler's Ford, Eastleigh, Hampshire, SO53 3LG, United Kingdom

PROMOTING INTEGRITY IN RESEARGH AND ITS PUBLIGATION 